\title{
Assessment of AIR Quality Index for Delhi region: A comparison between odd-even policy 2019 and Lock Down Period.
}

\author{
Chesta Dhingra \\ Email: - chesta_dhingra@sgtuniversity.org \\ Sanrachna Research and Policy Think Tank, Sri Guru Gobind Singh Tricentenary University
}

\begin{abstract}
The aim behind doing this research is to analyse the impact of odd-even policy and lockdown implementation on the air quality index of Delhi by doing the case study on the four regions Ashok Vihar, Anand Vihar, Dwarka and R.K. Puram. The data is been collected from DPCC and the main parameters we looked for are PM10 and PM2.5. In which we find out that highest levels of the pollutants PM10 and PM2.5 been observed during the time of odd-even policy implementation for the year 2019 (04 November 2019- 15 November 2019) whereas during the lockdown period (23 March 2020-31st August 2020) a great decline in pollutant levels is been detected. This we further try to correlate with the spatial variations of Delhi region and able to discern that meteorological parameters (Ambient Temperature, Relative Humidity, Wind Speed and Solar Radiations) in respect with seasonal variations have a major influence on PM 10 and PM 2.5 levels. During the winter season both the parameters PM10 \& PM2.5 are touching the peak because of the impact of three major meteorological parameters Ambient Temperature, Wind Speed and Solar Radiation and during the monsoon season air quality conditions are quite favourable because of Ambient Temperature and Wind Speed parameters. In the end we use the ensembled machine learning algorithms like Random Forest and Extra trees regressor to have an accurate estimation of PM2.5 levels for all the four regions of Delhi and perceived that these ensembled learning techniques are better than other machine learning algorithms like Neural Networks, Linear regression and SVMs. The Random Forest and Extra trees regressor models give the $\mathrm{R}^{2}$ value 0.75 and 0.78 respectively for estimation of PM2.5; $\mathrm{R}^{2}$ value is a statistical measurement which explains the variance of dependent variable based on the independent variables of a regression model.
\end{abstract}

Keywords: - Random Forest Algorithm, Extra Regressor Trees Algorithm, Outliers, Quantile method and Spatial Variation 


\section{Introduction}

Air Quality Index is a tool that measures the quality of air for a particular region. It describes the quality of air in terms of a categorical variable that has six distinguished factors knowns as "good", "Satisfactory", "Moderately polluted", "Poor", "Very Poor" and "Severe" and the major concern to look into or to monitor the air quality is whether national ambient air quality (NAAQs) standards are being met or not. According to the WHO, lower- and middle-income countries are more prone to the hazardous effects of air pollution and it also states that ambient air pollution is the major cause of death for approximately 4.2 million people in a year globally (WHO, Air Pollution). For India, situation is quite worse because every year approximately six million premature deaths occur due to hazardous effects of outdoor air pollution (Hama, Sarkawt M.L., et al 2020).

Outdoor air pollution has a significant impact and a direct linkage with the cardiovascular disorders $\&$ deaths and also the key factor in causing severe pulmonary diseases, lung cancer as well as acute respiratory illness ( $\underline{\mathbf{W H O}}$, Air Pollution). Air pollution and the particulate matter specifically PM 2.5 and pollutants below 2.5 microns are termed as carcinogenic to human beings. Thus, air quality is becoming a primary global concern because by reducing the air pollution we will directly be able to control and tackle the major environmental health risk for non-communicable diseases and will also be able to prevent more of morbidities and premature mortality which cause by ambient air pollution.

Quality of air is becoming a major concern for the indigenous people of Delhi because it not only impacts the environmental conditions but also has a disastrous impact on the health of human beings. In recent years we have seen increase in trends of natural cause - mortality and morbidity with more escalation of air pollution and particulate matter in Delhi over the years (Barnes,Jo, et al 2018). New Delhi is classified as the fifth most polluted cities in the world according to World Air Quality report 2019 (IQAir, World Air Quality Report 2019). According to a study conducted by World Bank Development Research Group the average of total suspended particulate matter for New Delhi region is always five times higher than World Health Organization's average standard (Gupta, Kumar Sanjiv, et al 2013) and this is the major reason that New Delhi has witnessed an average six-year loss of lives' expectancy which is two times higher than national level (Chate, D.M., et al 2016).

Thus, air pollution is the major factor of continuous environmental degradation as well as health deterioration. Weather is one of the important reasons which also helps in exacerbate 
the air pollution situation particularly during the winter months(Barnes,Jo, et al 2018). More air pollution and smog are becoming a generic phenomenon during the winter months and it is leading to more of acute respiratory illness and pulmonary diseases because of extreme air pollution events. To describe the severity of air pollution situation in New Delhi at the time of fall season international and national media quoted it as "Delhi Air pocalypse" or "Death by breath" (Barnes,Jo, et al 2018). Though these are some of the short span extreme events which get to be noticed on global basis but Delhi's air quality remains very poor throughout the year.

One of the major contributors which aggravates the air pollution condition in Delhi is the industrial waste as Delhi has the higher number accumulation of small-scale industries and second is the power plants specifically coal based ones within the vicinity of Delhi, furthermore the rise in PM10 level is caused by road dust which accounts for 50\%, industry that accounts for $23 \%$ and lastly vehicular pollution which accounts for only $7 \%$ (Gharad, Pratahmesh, et al, 2016). The major contributors for PM 2.5 are dust particles, domestic fuel burning, burning of Municipal Solid Waste (MSW), industrial pollution and vehicular transmission. The neighbouring states of New Delhi like Haryana and Uttar Pradesh are also aiding in worsening the situation of PM 2.5 and leads to enhancement in ambient air pollution because a significant amount of PM 2.5 comes from these states as well (Barnes,Jo, et al 2018). Two neighbouring states i.e., Haryana \& Punjab which are the largest producers of rice and wheat in northern India and also the major contributors (approx. 48\%) of smog and air pollution caused due to stubble burning (Chaki, Sukalpaa, et al, 2020). Some of the other key factors which are aggravating the air degradation condition in Delhi is the rapid growing population that is further linked with expansion of urbanization and city infrastructure.

In this paper we are analysing the patterns of AQI specifically the concentration levels of PM 2.5 and PM 10 during the implementation of odd - even policy from $4^{\text {th }}$ November 2019 to $15^{\text {th }}$ November 2019 under the guidance of Delhi Government and during the lock down period at the time of covid19 pandemic from $23^{\text {rd }}$ March 2020 till $31^{\text {st }}$ August 2020. To have a detailed overview that how much policy intervention is effective in curbing the air pollution and how drastically AQI patterns been impacted during the lock down period. The intervention of this odd-even policy has been started in the year 2016 and has been implemented since then. The vehicles with odd number plate will run on odd days and vehicles with even number plate run on even days (the last digit of the number plate will be looked for the bifurcation). In this we are analysing the trends and the median differences between control years and the treatment duration. 
Secondly, we are trying to relate how weather conditions like Ambient Temperature, Relative Humidity, Barometric Pressure, Solar Radiation, Wind Direction and Wind Speed are impacting the AQI parameters during different seasons. In this we are trying to observe that how spatial variations in association with meteorological parameters correlated with Air Quality Index Parameters. Because topography of Delhi is quite unique as on the Northern Region it is surrounded by the Himalayan Range \& on its southern side it is surrounded by hot peninsular region which accentuate its climatic conditions being very hot during the summer seasons which lasts from $21^{\text {st }}$ March till $15^{\text {th }}$ June, dry winter cold seasons which lasts from 26 November to $9^{\text {th }}$ February and lastly the monsoon humid season which starts by the end of June.

Lastly in this paper we are doing the estimation of AQI parameter PM 2.5 and how accurately we can predict or estimate its concentration levels using the ensembled approach of machine learning algorithm Random Forest Regressor and Extra tree regressor.

The parameters which have been taken into consideration for the analysis of AQI data are Ambient Temperature (AT), Barometric Pressure (BP), PM10, PM2.5, Relative Humidity (RH), Solar Radiation (SR), Wind Direction (WD), Wind Speed (WS), NOx, NO, $\mathrm{NO}_{2}, \mathrm{CO}$, $\mathrm{NH}_{3}$, Ozone and $\mathrm{SO}_{2}$. The data has been collected from Central Control Room for Air Quality Management - Delhi NCR and the Delhi Pollution Control Committee (DPCC) stations both for industrial, institutional and residential area. The areas which have been selected are Ashok Vihar, Anand Vihar, Dwarka Sector 8 and R.K. Puram.

\section{Methodology}

\section{Data Collection and Analysis}

The hourly data for Ambient Temperature (AT), Relative Humidity (RH), Solar Radiation (SR), Wind Speed (WS), Wind Direction (WD), NH3, NOx, NO, NO2, SO2, CO and Ozone have been collected from $1^{\text {st }}$ January 2019 to $8^{\text {th }}$ December 2020 from four air quality stations of Delhi.

The data for air quality monitoring stations has been collected from the Central Pollution Control Board (CPCB) site and data is been monitored by Delhi Pollution Control Committee (DPCC) for all the four stations on which the analysis been conducted

1) Ashok Vihar station falls under Institutional and Residential Category

2) R.K. Puram station falls under Residential Category 
3) Anand Vihar under the Hotspot category

4) Dwarka Air Quality Monitoring station under Commercial and Residential Category

The data before analysing is been cleaned and inspected for any missing values. The missing values been imputed before any further analysis and interpretation using the open software packages of Python. The main parameters of AQI that we are analysing in this paper are PM10 and PM 2.5 levels and how the policy interventions, lockdown duration, meteorological variables and spatial variations have impacted them.

For the analysis the daily median values and weekly median been observed for each station during the implementation of odd-even policy for the 2019 year and lockdown duration for the year 2020. Median is one of the measures of central tendency and it is more robust $\&$ rigid as compared to the average values because the outliers and skewed data have a smaller impact on median in comparison to average values.

To be more precise with the analysis for this pattern detection and trends of PM10 and PM2.5 during the policy and lockdown interventions outliers or the extremities been detected using the percentiles or quartiles method. This anomaly detection is an important task because these are the unusual datapoints in the data and are important specifically when we try to study the meteorological conditions with Air quality parameters to have knowledge that how weather conditions can have major impact on air quality conditions of Delhi. In this we have used the common univariate boxplot rule for the outlier detections and in this percentile method data is divided into four groups $25^{\text {th }}, 50^{\text {th }}$ and $75^{\text {th }}$ percentile and the Interquartile Range is difference between the $25^{\text {th }}$ percentile and $75^{\text {th }}$ percentile. We identify the outliers by defining limits on the sample values and in this we have defined the upper limit as 0.95 and lower limit as 0.05 . By defining the limits, we get the data values which are above the 95 percentile (upper limit) and below the 5 percentile (which is the lower limit) which we consider as outliers.

In depth details of spatial and meteorological characteristics been evaluated with the concentration levels of PM10 and PM2.5 using the Pearson Correlation Coefficient (r) which indicates the relationship between the two variables with same intervals or having the same ratio scale. It shows the strong association between two continuous. This is a mathematical correlation coefficient and denote the two continuous variables as $\mathrm{X}$ and $\mathrm{Y}$. The (r) coefficient range from -1 to +1 ; where -1 denotes the strong negative correlation between the variables $\mathrm{X}$ and $\mathrm{Y}$ in which if one variable is moving upwards other will be moving downwards (shows inverse relationship); whereas +1 denotes the strong positive correlation having the positive or 
direct effect on both the variables. For this all the variables been scaled of the data which means standardization of data has been done moreover, standardization does not have effect on outliers of the data. Standardization is been done by deducting the mean and scaling the data by the variance feature $\left(\mathrm{Z}_{\mathrm{i}}\right)$ and this is calculated as: -

$$
\mathrm{Z}_{i}=\frac{x_{i}-x}{\delta_{x}}
$$

Lastly, for the estimation of PM2.5 level the ensembled based machine learning approach is used to predict the PM2.5 level using the random forest and extra trees regressor technique and moreover, these ensembled approaches also able to perform the factorial analysis which is also known as multiple component analysis that helps in extracting the important features from the data for predicting the dependent variable. The Random Forest technique is a supervised learning approach which can be used for both regression and classification analysis. These ensembled techniques perform way better than the Regression; Time Series; and Autoregressive Integrated Moving Average (ARIMA) because these ensemble learning algorithms have the ability to overcome non-linearity behaviour of the pollutants and meteorological factors quite efficiently (Bashir, Barjeece, et al, 2019). Also have quite good efficiency in estimating the PM2.5 level. These ensembled techniques performed better than Artificial Neural Networks and Support Vector machines because it combines the strong \& weak independent variables which are more prone to overfitting and make a good generalization of the independent parameters while making the prediction for dependent variable; maintains the good accuracy level by slightly increasing the biasness and decreasing the variance among the predictors (Masih, A, 2019).

\section{Results and Discussion}

Figure 1 is the heat map of all the four regions taken for case study of Delhi that is Ashok Vihar, Dwarka, Anand Vihar and R.K. Puram during the time of odd-even policy $\left(4^{\text {th }}\right.$ November 2019- $15^{\text {th }}$ November 2019) intervention where it is not able to make an impact on Air Quality Index of Delhi as the values on daily median basis for both the parameters PM10 \& PM2.5 are touching the average level above $400 \& 250$ respectively for all the regions. In addition to that PM10 had touched the peak of 700 micrograms per metre cube for Dwarka, Ashok Vihar \& Anand Vihar, whereas for R.K. Puram PM10 touched 500 micrograms per metre cube during the week of odd-even policy implementation; PM2.5 it had touched the levels of 400 micrograms per metre cube for Dwarka, Ashok Vihar and Anand Vihar whereas 
for Dwarka it had touched 350 micrograms per metre cube. So, there is no clear consensus that implementation of this policy does bring some significant reductions in the pollutant levels (Gulia, Sunil, et al 2017).
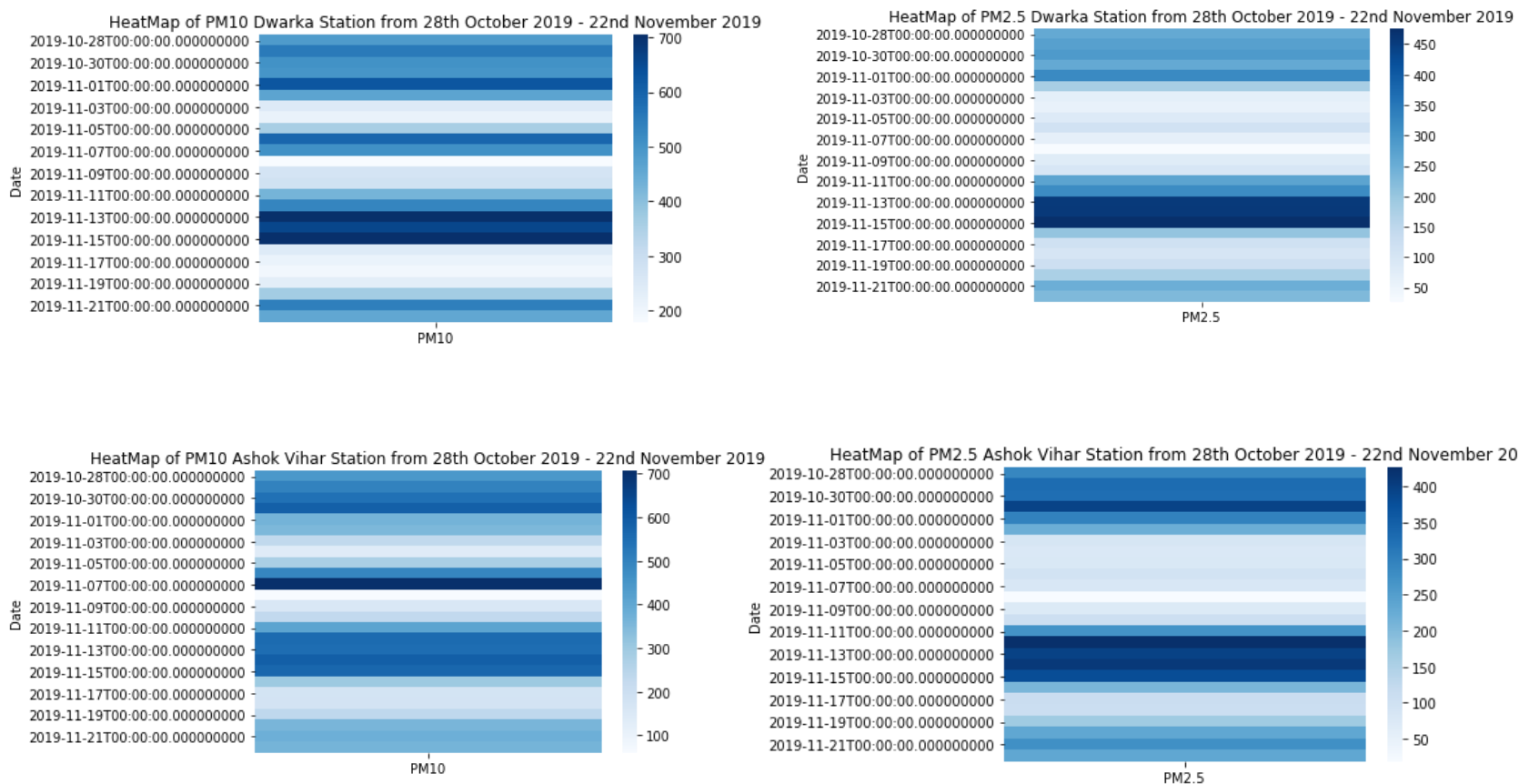

HeatMap of PM10 R.K.Puram Station from 28th October 2019 - 22nd November 2019 2019-10-28T00:00:00.000000000 2019-10-30T00:00:00.000000000 2019-11-03T00:00:00.000000000 2019-11-05T00:00:00.000000000 2019-11-07T00:00:00.000000000

2019-11-09т00:00:00.000000000 2019-11-11T00:00:00.000000000 2019-11-13т00:00:00.000000000 2019-11-15T00:00:00.000000000 2019-11-17T00:00:00.000000000 2019-11-19т00:00:00.000000000 2019-11-21T00:00:00.000000000

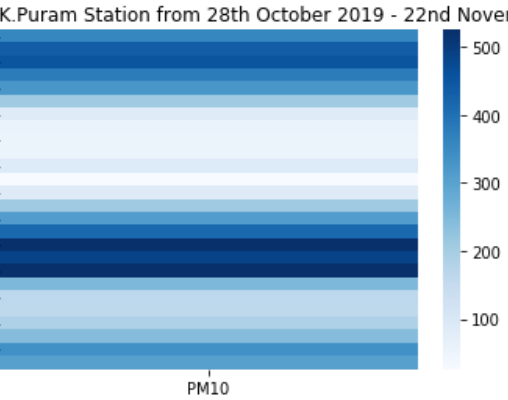

PM10
HeatMap of PM2.5 R.K.Puram Station from 28th October 2019 - 22nd November 2019 2019-10-28T00:00:00.00000000 2019-10-30T00:00:00.000000000 2019-11-01T00:00:00.000000000 2019-11-05T00:00:00.000000000 2019-11-07T00:00:00.000000000

2019-11-09т00:00:00.000000000

落 2019-11-11T00:00:00.000000000 2019-11-13T00:00:00.000000000 2019-11-15T00:00:00.000000000 2019-11-17T00:00:00.000000000 2019-11-17T00:00:00.000000000 2019-11-19T00:00:00.000000000

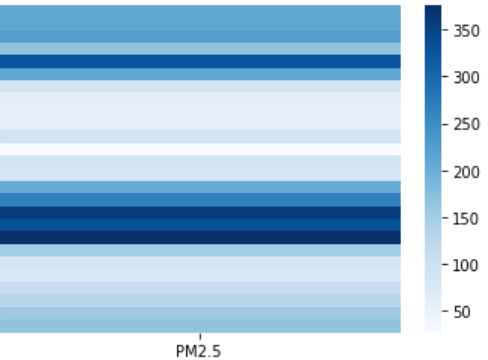

PM2.5

HeatMap of PM2.5 Anand Vihar Station from 28th October 2019 - 22nd November 2019

HeatMap of PM10 Anand Vihar Station from 28th October 2019 - 22nd November 2019 2019-10-28T00:00:00.000000000 2019-10-30T00:00:00.000000000 2019-11-01T00:00:00.000000000 00:00:00.00000000 11-05T00:00:00.000000000 9-11-07T00:00:00.000000000 2019-11-09т00:00:00.000000000 2019-11-11т00.00-00000000000 2019-11-13T00:00:00:000000000 2019-11-15T00:00-00-000000000 2019-11-17T00:00:00.000000000 2019-11-19т00:00:00.000000000 2019-11-21T00:00:00.000000000

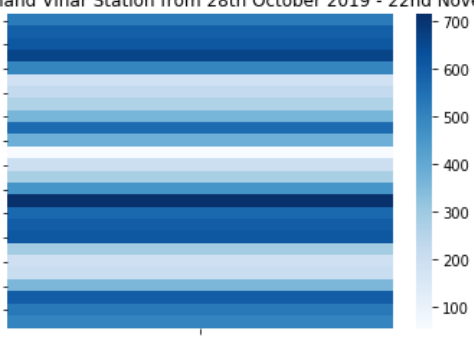

PM10

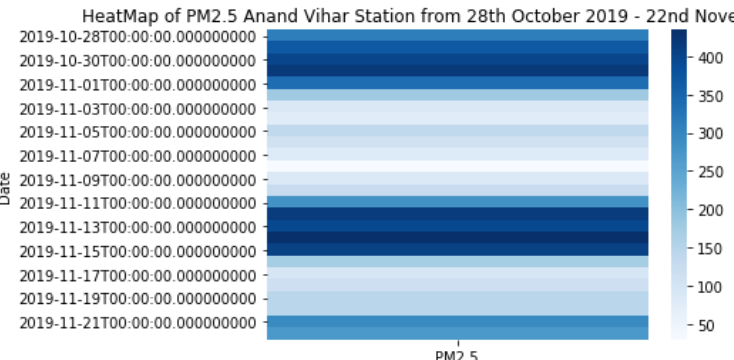

PM2.5

Figure 1 Heatmaps of all the stations that has been taken for case study for the pattern detection of PM2.5 and PM10 level during the implementation of odd-even policy in Delhi in the year 2019 ( $4^{\text {th }}$ November $2019-15^{\text {th }}$ November 2019). We have taken seven days before and after the policy intervention to know in detail that how much impact does this treatment have on the AQI of Delhi 
To be more accurate with insights of the AQI data for both the parameters for 2019 during execution of policy we look at the dummy variable that is weekly number median values for all the four stations in the Figure 2 which shows that there is no significant reduction been observed for PM10 and PM2.5 for the week numbers 44, 45, 46, 47.
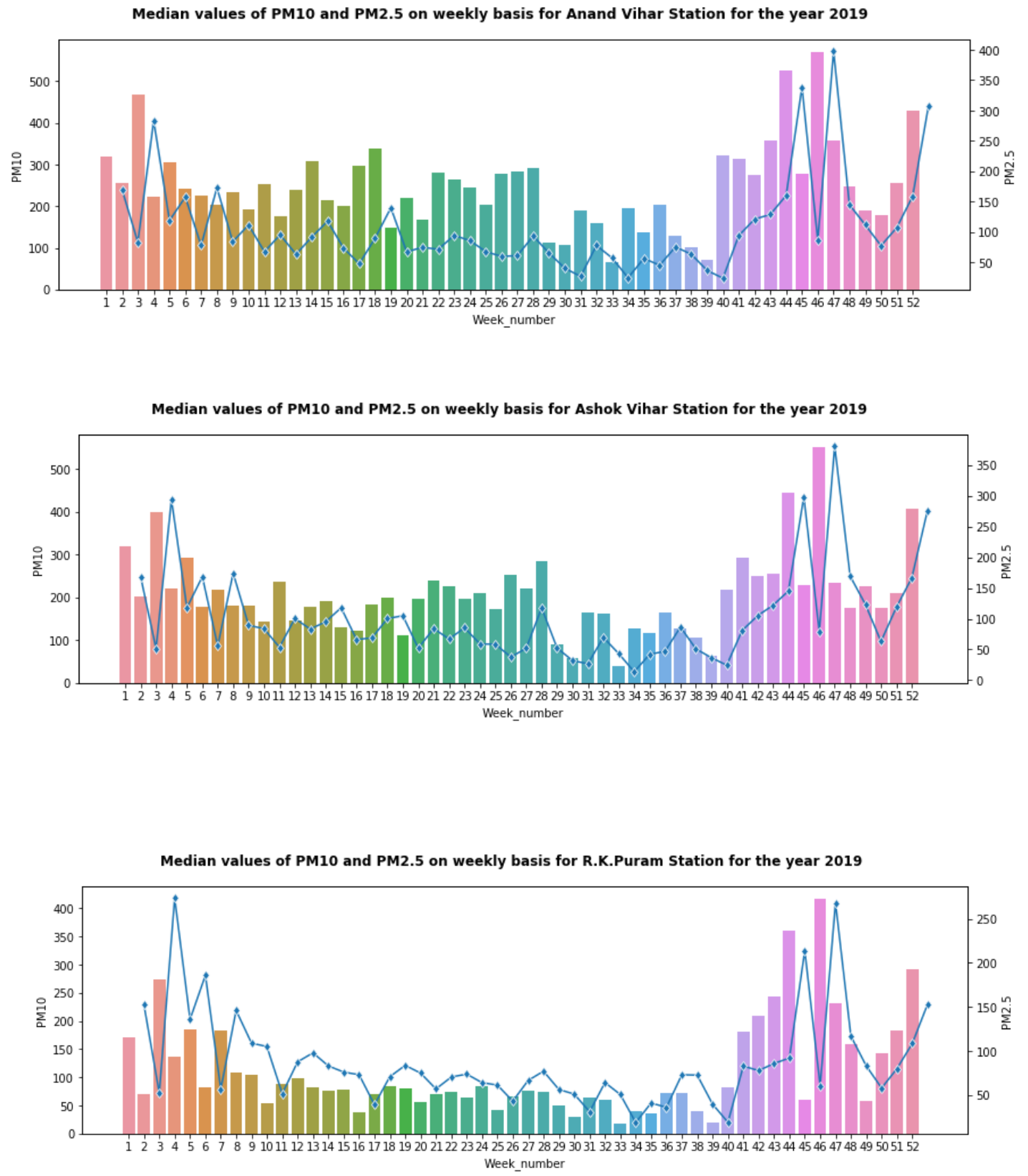


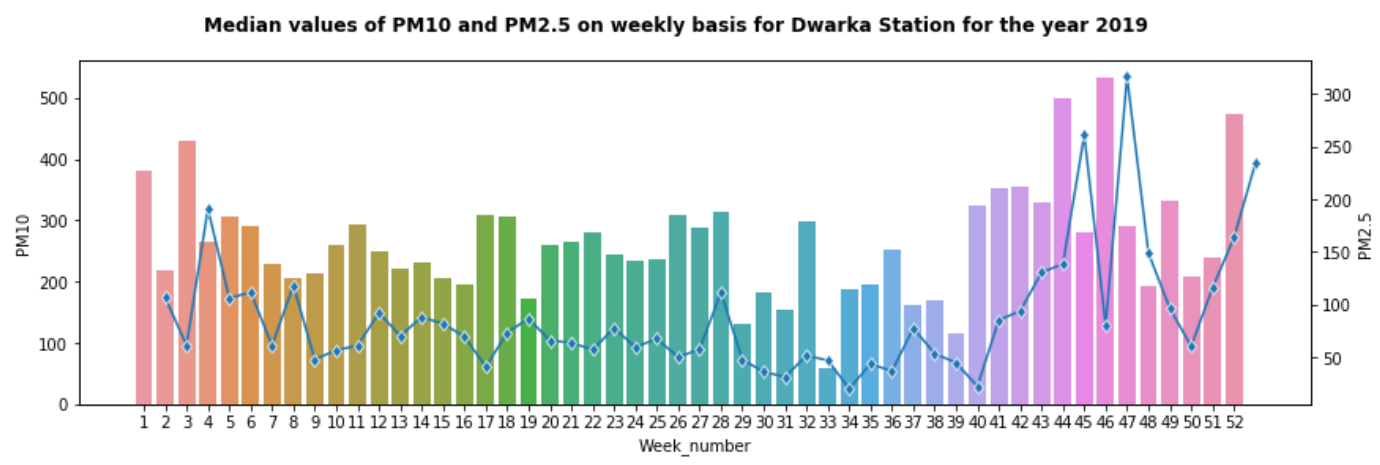

Figure 2 Weekly median values for the year 2019 for all the four regions in which we observe that for the week 45 and 46 in particular when enactment of policy had been done the median values are touching the bracket of poor air quality index except for the Dwarka station where the median value of PM10 is quite low during the week number 45 but PM2.5 touching the high of 200 above.

On the other hand, we are able to observe a great impact of lockdown situation on AQI parameters where the PM2.5 and PM10 had seen about 39\% and 60\% reduction respectively in the city ( Ghosh, Gopal Krishna, et al 2020) and in our analysis based on the median values on daily basis we have observed that PM2.5 touching the low of 50 microgram per metre cube or below that, whereas PM10 touching the low of 100 micrograms per metre cube even for the Anand Vihar which is one of the major hotspots to analyse the AQI parameters.

In Figure 3 the heatmaps of all the four regions from $23^{\text {rd }}$ March 2020 till $31^{\text {st }}$ August 2020 shows a great variation of touching a low for both the variables specifically during the monsoon period.
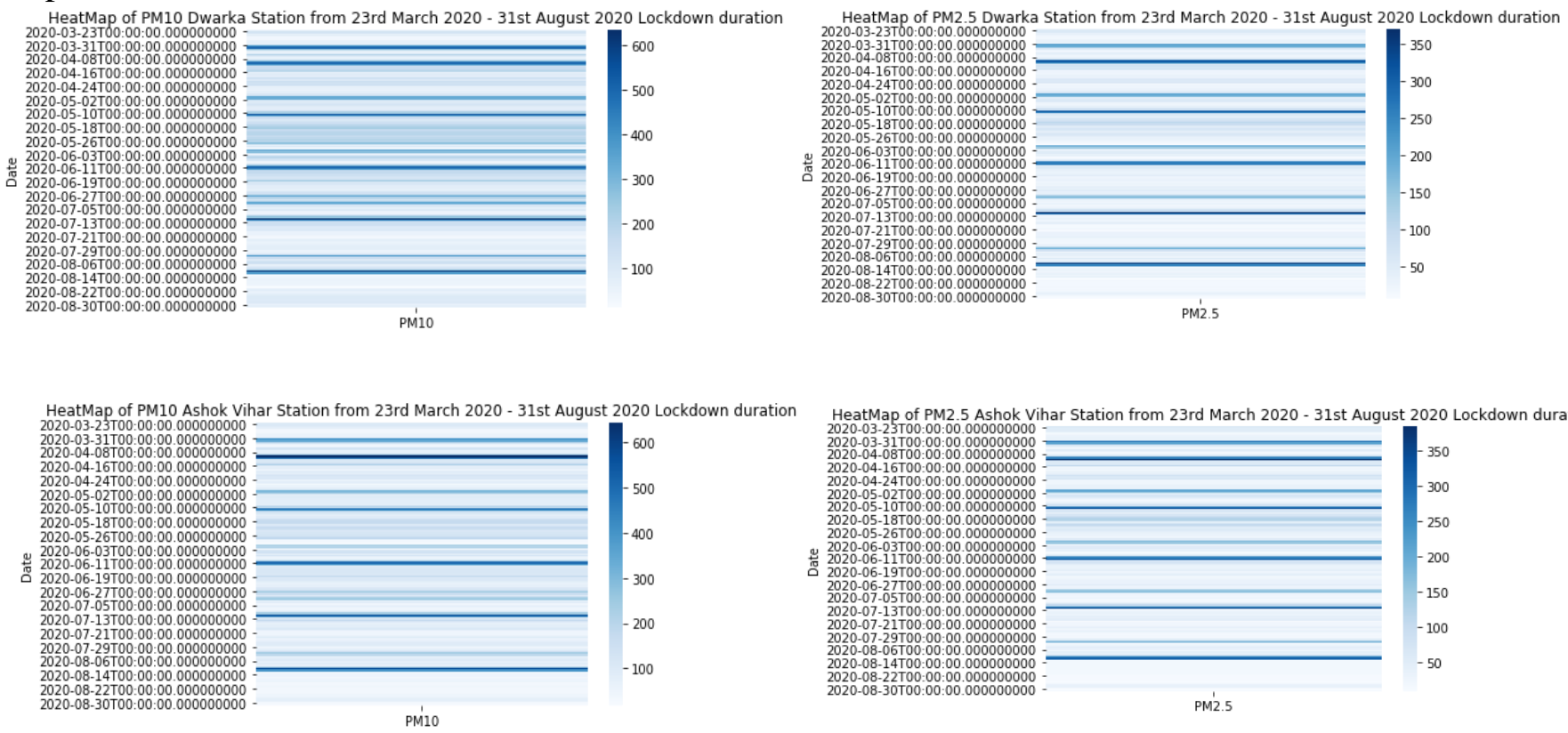

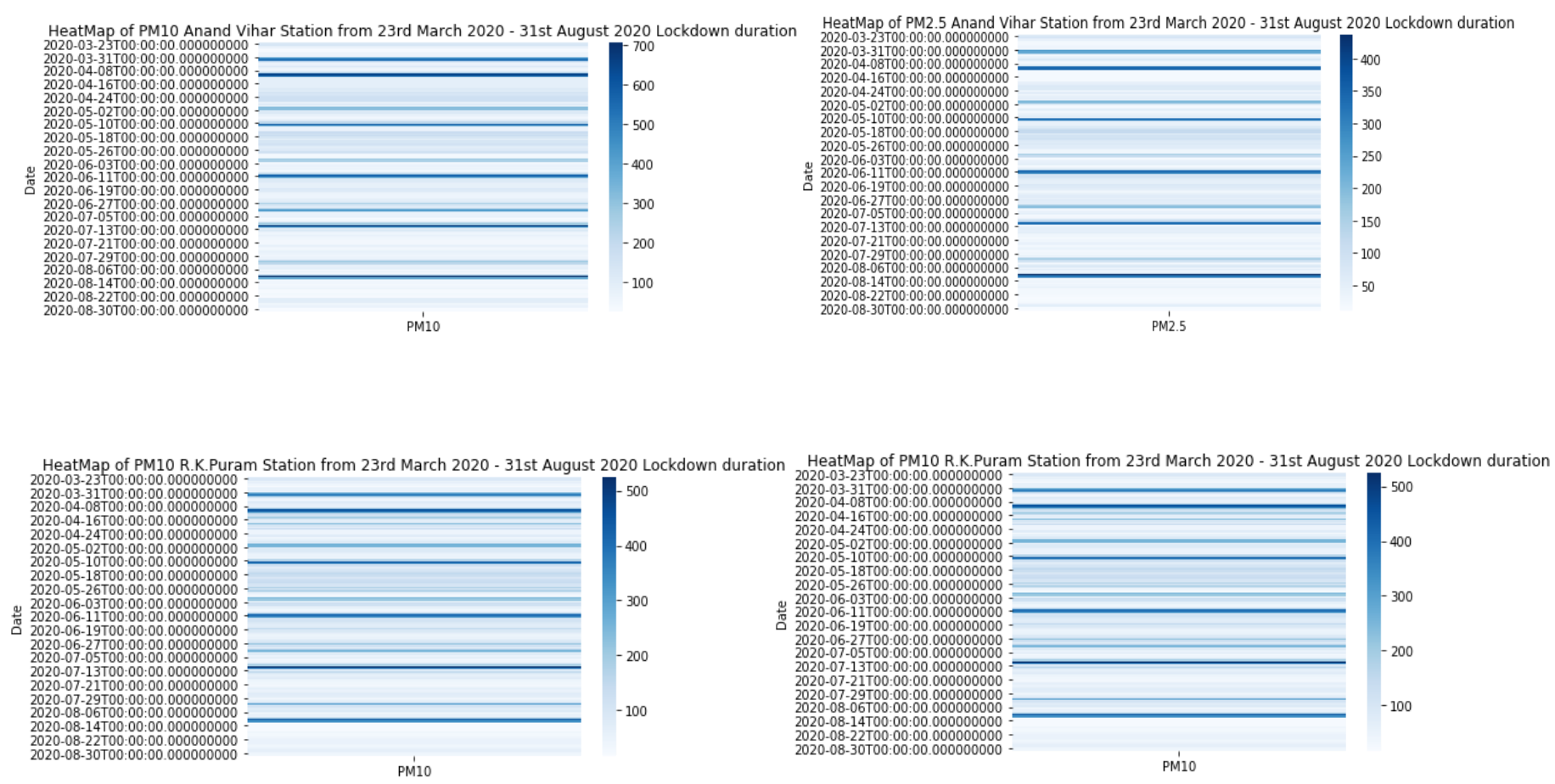

Figure 3 Heatmaps of all the four regions i.e., Dwarka, Ashok Vihar, Anand Vihar and R.K. Puram during the lock down period from $23^{\text {rd }}$ March 2020 to $31^{\text {st }}$ August 2020 which shows that for all the regions both the parameters PM10 and PM2.5 touched the level below 100 and 50 micrograms per metre cube at various intervals specifically during the monsoon season.

This shows that lockdown implementation is quite effective in comparison to the odd-even policy enactment because not only vehicles are responsible for air quality in Delhi but also other major factors like stubble burning, constructions, burning of wastes, thermal power plants in vicinity of Delhi moreover, the spatial variations and meteorological conditions plays an important role in effecting the Air Quality Index of Delhi.

In Figure 4 weekly median values remain quite low during the lockdown duration as well as during the monsoon period but it started to increase by the end of September and mid of October 2020 when stubble burning had started and there is arrival of winter season which exacerbate the air pollution condition of Delhi.

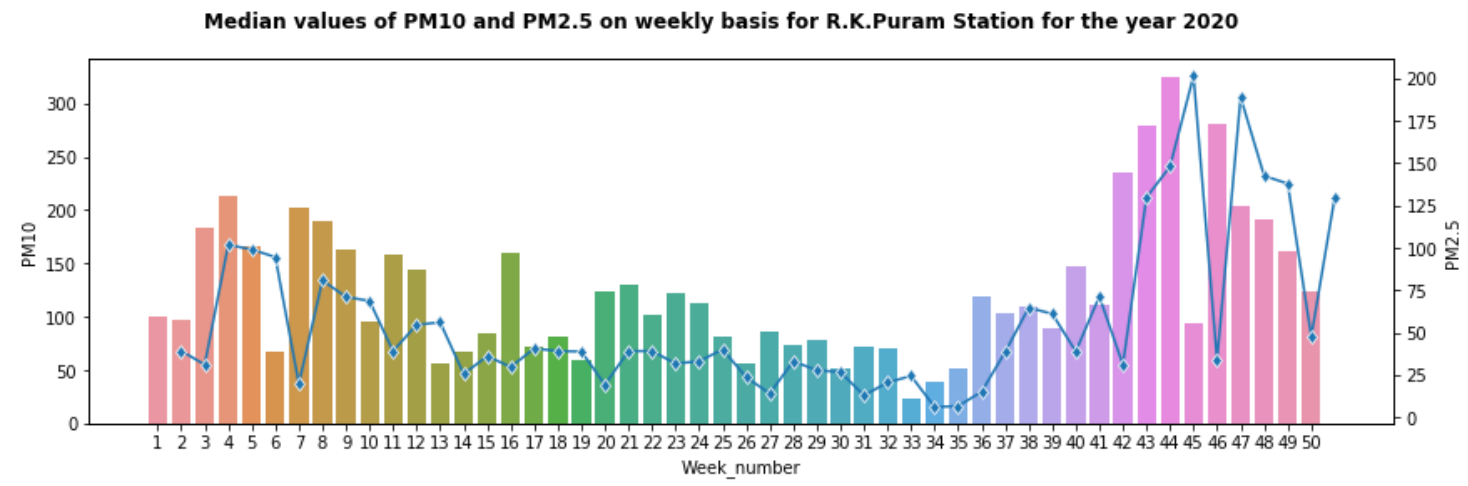




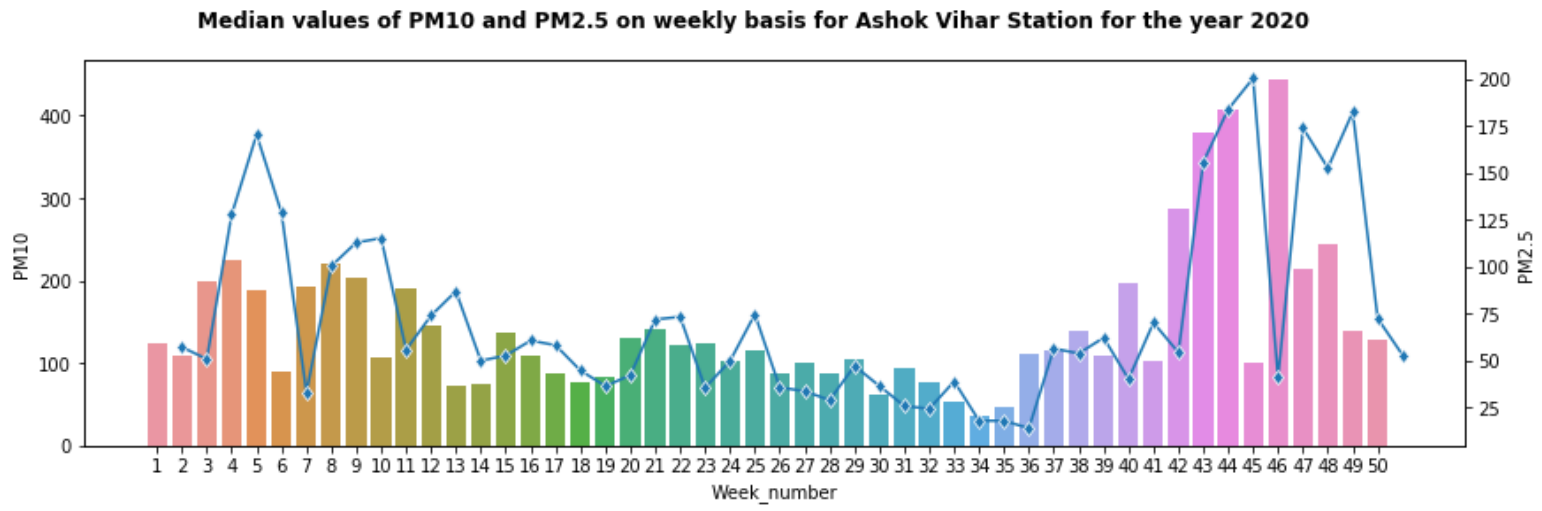

Median values of PM10 and PM2.5 on weekly basis for Dwarka Station for the year 2020

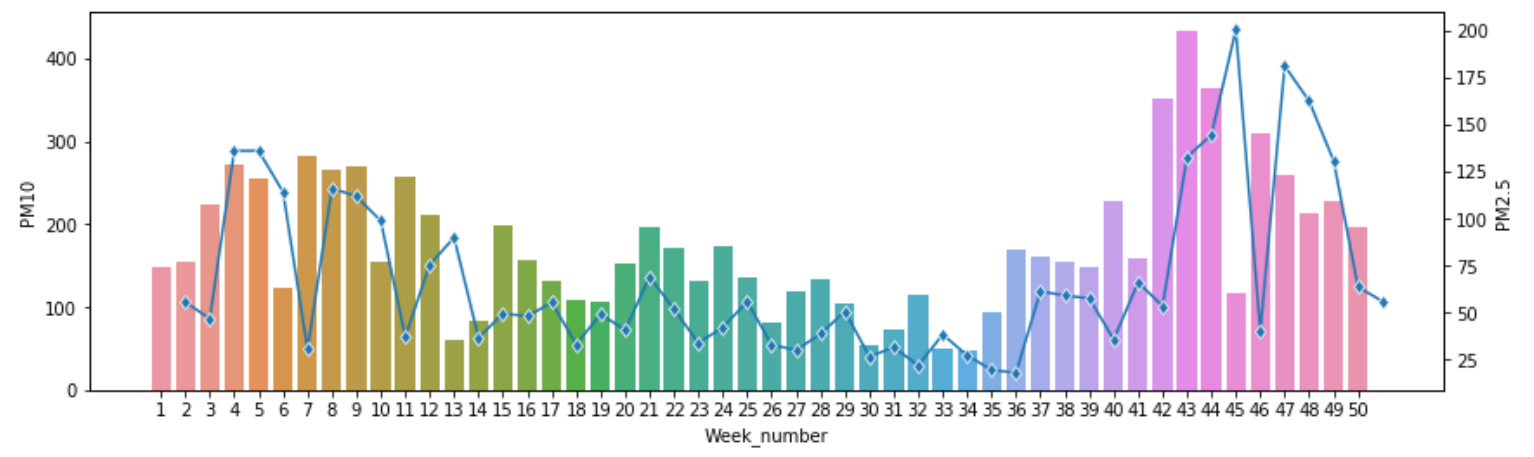

Median values of PM10 and PM2.5 on weekly basis for Anand Vihar Station for the year 2020

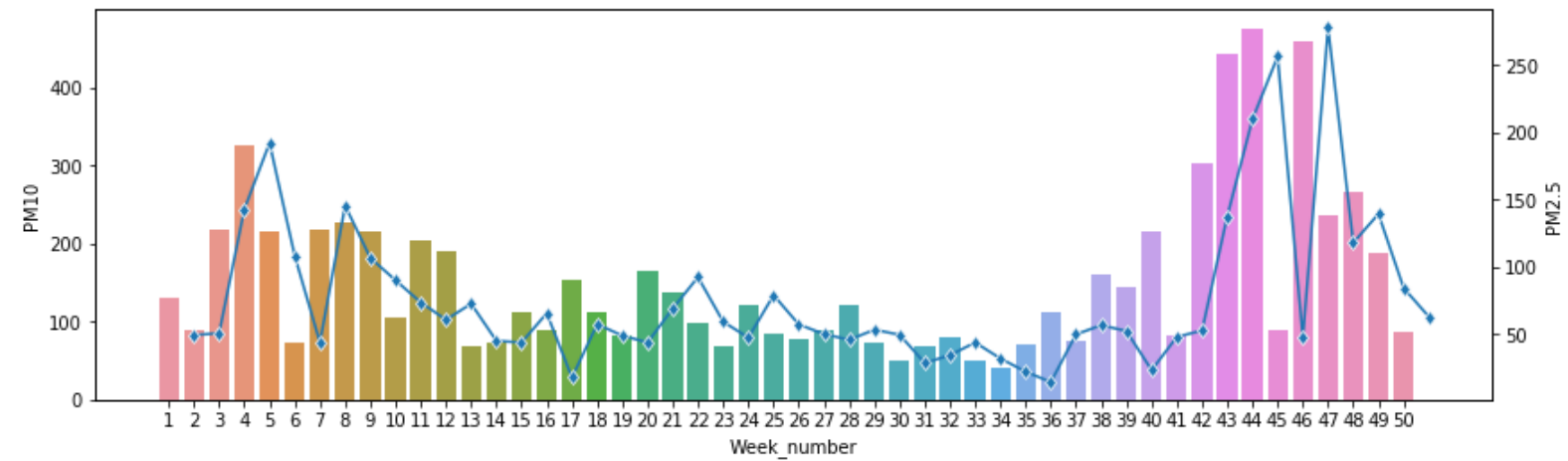

Figure 4 The maximum values of PM10 and PM2.5 had been observed during the winter season from January till mid of march and after lockdown we observed minimum values specifically during the monsoon seasons for all the stations where PM2.5 touched the level of 25 except for the Anand Vihar Station where it touched the level below 20 for PM2.5 or below it and for PM10 it had touched the level below 100 except for the R.K. Puram station where it touched the level below 50 for PM10. 
Thus, to analyse further regarding the spatial variation analyses firstly we have done the outlier detection using the percentile method in which the values above the 0.95 threshold level and below 0.05 threshold level is considered to be the outliers. Among which the most of values of the outliers above the threshold level of 0.95 or the extreme positive values for both the years 2019 and 2020 appeared in the winter season specifically during the months of October, November, January and February for which we can consider that highest concentrations of PM10 and PM2.5 occurred during the winter months and the least values of PM10 and PM2.5 been observed during the monsoon months specifically during the months of June, August and early mid of September which indicates that during monsoon months the concentration level of both the parameters is quite low(Gulia, Sunil, et al 2017). To have more deeper insights of these spatial variations and meteorological parameters with Air Quality Parameters the Pearson correlation is observed for the winter season, summer, monsoon and post monsoon and the correlation, mean, median, standard deviation and quantile values varied according to the season.

Fig 5, shows the coefficient $r$ value of Pearson correlation during the time of Winter January February 2019 shows a negative correlation of PM2.5 with Ambient Temperature (AT) -0.35 and significant negative correlation of Wind Speed (WS) parameter with PM10 (-0.25), PM2.5 (-0.39), $\mathrm{NO}(-0.37), \mathrm{NO}_{2}(-0.28)$ and $\mathrm{NOx}(-0.36)$; even during the Winter time for 2020 from $15^{\text {th }}$ October 2020 to $8^{\text {th }}$ December 2020 in which stubble burning events had also be taken place which showed a significant negative correlation of PM10 (-0.35) and PM2.5 (-0.34) with Solar Radiation (SR), negative correlation with AT (PM10 -0.28; PM2.5 -0.37) and WS parameter has negative correlation with PM10 (-0.42), PM2.5 (-0.43), NO (-0.37), $\mathrm{NO}_{2}(-0.45)$ and NOx (-0.42).

In spring summer season for the year 2019 PM2.5 has shown negative correlation with AT i.e., -0.45 whereas PM10 doesn't have the significant relationship with AT for the summer season; Relative Humidity on the other hand has significant positive relationship with PM2.5 (0.27). Summer spring 2020 gives some significant results AT has strong negative correlation with PM10 (0.46), PM2.5 (0.5) whereas significant negative correlation with the NO (-0.42), $\mathrm{NO}_{2}$ (-0.34) and NOx (-0.44); RH has good positive impact on PM2.5 (0.33) and PM10 (0.25); WS has significant negative impact on PM10 (-0.39) and PM2.5 has -0.41 .

During the monsoon season for the year 2019 the results of the Pearson Correlation shows that AT has negative impact on PM2.5 (-0.46); WS does have negative correlation with PM10 (- 
0.23); PM2.5 (-0.34); Relative Humidity does not have significant impact on PM2.5 but does have negative impact on PM10 (-0.34); Wind Direction (WD) has significant positive impact on PM2.5 (0.38) and PM10 (0.41). For the year 2020 Ambient Temperature does show significant negative impact on both the parameters which is PM10 (-0.46) and PM2.5 (-0.5); RH shows positive impact on PM10 (0.25) and PM2.5 (0.33) and WS has strong negative correlation with PM10 (-0.39) and PM2.5 (-0.41).

Post Monsoon 2019 shows significant positive correlation of RH with PM2.5 (0.38) and PM10 (0.22); this season also does show a strong positive impact of Solar Radiation (SR) with other AQI parameters $\mathrm{NO}(0.34), \mathrm{NO}_{2}(0.47)$ and $\mathrm{NOx}(0.38)$, does show a negative correlation of AT with PM2.5 (-0.34). For the post monsoon season of 2020 AT has shown a great negative correlation with PM10 (-0.46) \& PM2.5 (-0.49); WS also showed negative impact on PM10 ($0.36)$ and PM2.5 (-0.27).

Winter 2019 and 2020 (December 2019 - February 2020) shows a significant negative impact of AT with PM2.5 (-0.46) and PM10 (-0.37); RH positive impact on PM2.5 (0.42), PM10 (0.26); SR has negative impact on PM2.5 (-0.17) and PM10 (-0.15); lastly, WS has important negative correlation with PM2.5 (-0.35) and PM10 (-0.28).

Thus, we have seen that with spatial variations value of $r$ coefficient has changed between the meteorological and AQI parameters but there are some specific parameters like Ambient Temperature, Wind Speed, Solar Radiation (during some particular season like Winter) and Relative Humidity have played an important role in increasing and decreasing both the AQI parameters i.e., PM10 and PM2.5.

Table 1 shows the seasonal statistical summary of PM10 and PM2.5 which shows that more variations been observed during the post monsoon season and winter season because of the stubble burning and meteorological conditions as low temperature has an inverse relationship with both PM10 and PM2.5 parameters (Hama, Sarkawt M.L., et al 2020) (2019- PM10 mean- 243.64, std- \pm 142.6 , median- 218.3, PM2.5 mean- 138.8, std- \pm 100.77 , median- 109.6; 2020 - PM10 mean- 273.45, std- \pm 147.91 , median- 272.31; 2020 PM10 mean- 273.45, std\pm 147.91 , median- 272.31, PM2.5 mean- 150.71, std- \pm 93.03 , median- 148.25; Winter 20192020 PM10 mean- 250.72, std- \pm 148.68 , median- 217.43, PM2.5 mean- 140.77, std- \pm 103.60 , median- 110.25). Monsoon season shows less of variations because of the significant meteorological conditions on the PM 10 and PM2.5 variables (Hama, Sarkawt M.L., et al

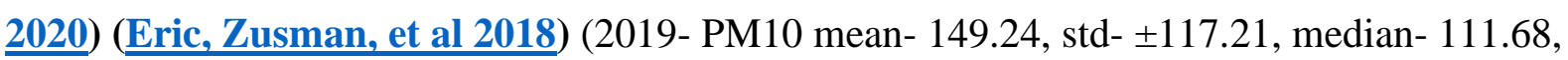


PM2.5 mean- 63.70, std- \pm 59.11, median- 43.31; 2020- PM10 mean- 121.78, std- \pm 124.90 , median- 78.56, PM2.5 mean- 57.16, std- \pm 80.58 , median- 32.25$)$. Besides all the other factors like small scale industrial pollution, domestic fuel burning, construction, dust, burning of Municipal Solid Waste (MSW) and vehicular pollution meteorological conditions or weather parameters plays a significant role in determining the quality of AQI in Delhi.

Pearson Correlation Graph for Jan Feb 2019

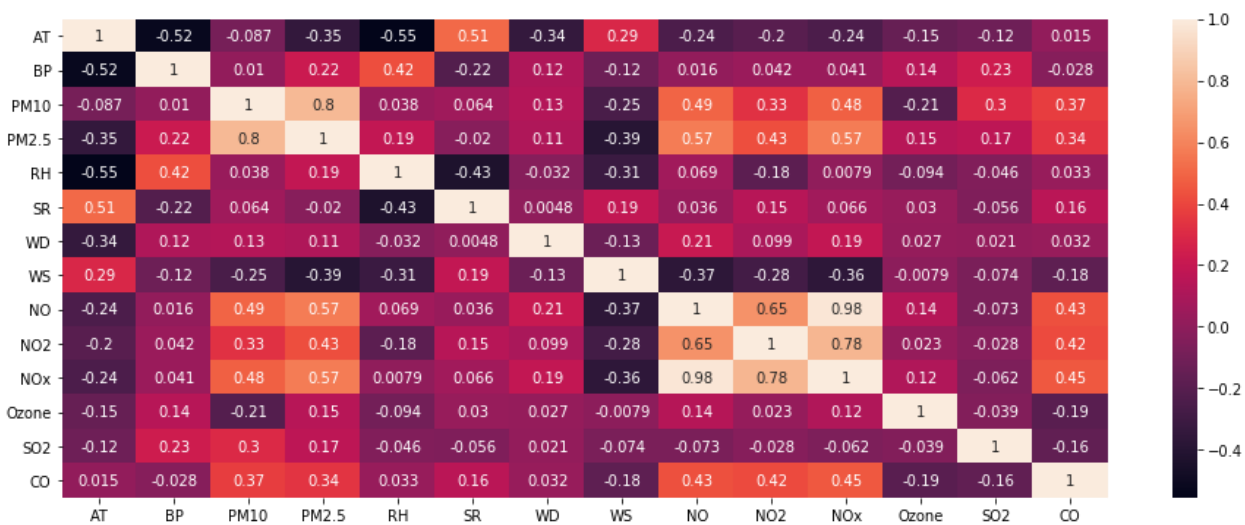

Pearson Correlation Graph for Spring Summer season 2019(01 March 2019-30 June 2019)

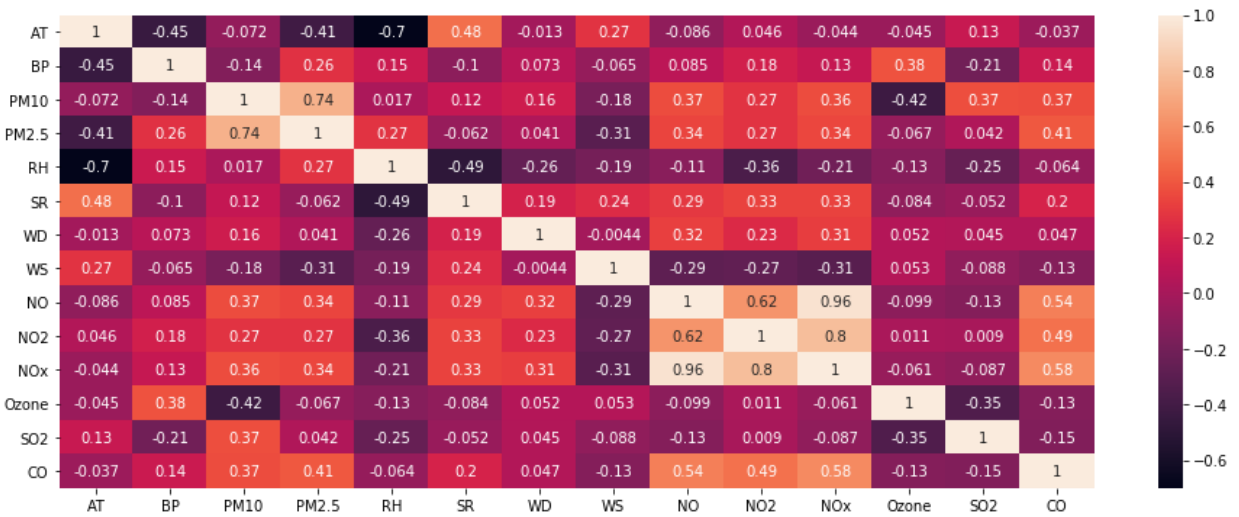

Pearson Correlation Graph for Monsoon season 2019(01 July 2019-30 September 2019)

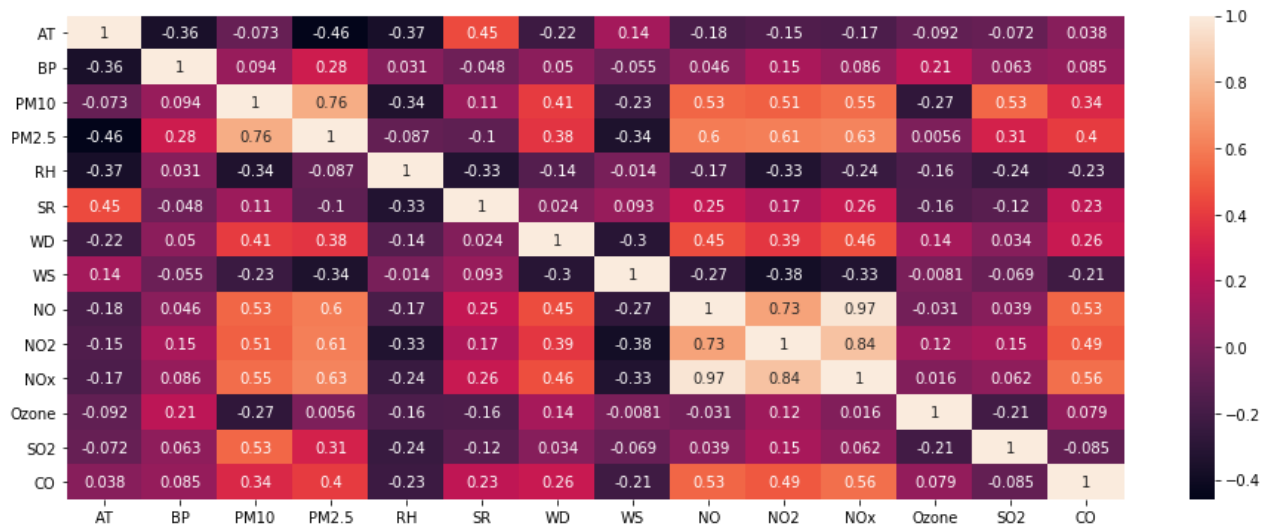


Pearson Correlation Graph for Post Monsoon season 2019(01 October 2019-30 November 2019)

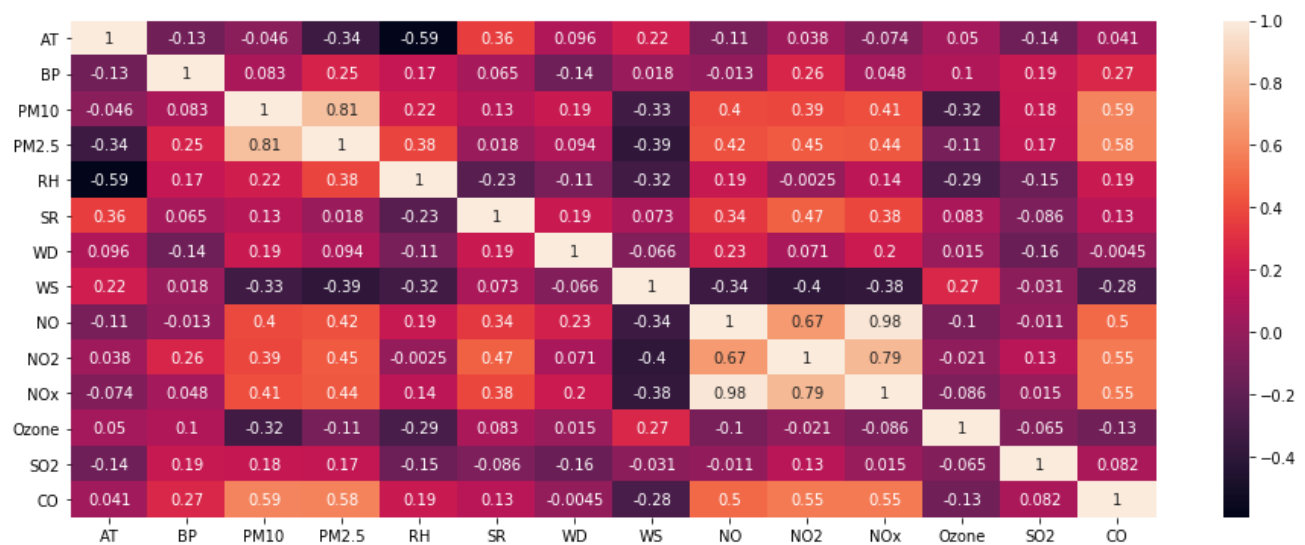

Pearson Correlation Graph for Winter season 2019-2020 (01 December 2019-28 February 2020)

\begin{tabular}{|c|c|c|c|c|c|c|c|c|c|c|c|c|c|c|}
\hline AT - & 1 & -0.2 & -0.37 & -0.46 & -0.62 & 0.33 & -0.082 & 0.2 & -0.19 & -0.17 & -0.2 & 0.23 & 0.13 & -0.086 \\
\hline$B P$. & -0.2 & 1 & 0.13 & 0.18 & 0.099 & -0.28 & -0.18 & -0.11 & -0.12 & 0.05 & -0.062 & 0.036 & 0.13 & -0.085 \\
\hline PM10 & -0.37 & 0.13 & 1 & 0.91 & 0.26 & -0.15 & 0.037 & -0.28 & 0.47 & 0.4 & 0.5 & -0.17 & 0.13 & 0.52 \\
\hline PM2.5 & -0.46 & 0.18 & 0.91 & 1 & 0.42 & -0.17 & -0.067 & -0.35 & 0.45 & 0.43 & 0.49 & -0.052 & 0.075 & 0.5 \\
\hline $\mathrm{RH}$. & -0.62 & 0.099 & 0.26 & 0.42 & 1 & -0.28 & -0.018 & -0.4 & 0.2 & 0.18 & 0.2 & -0.23 & -0.34 & 0.2 \\
\hline SR & 0.33 & -0.28 & -0.15 & -0.17 & -0.28 & 1 & 0.11 & 0.25 & 0.088 & 0.12 & 0.11 & 0.17 & -0.069 & 0.094 \\
\hline WD - & -0.082 & -0.18 & 0.037 & -0.067 & -0.018 & 0.11 & 1 & -0.14 & 0.16 & 0.17 & 0.18 & -0.019 & -0.11 & 0.087 \\
\hline ws & 0.2 & -0.11 & -0.28 & -0.35 & -0.4 & 0.25 & -0.14 & 1 & -0.21 & -0.17 & -0.23 & 0.14 & -0.068 & -0.14 \\
\hline NO & -0.19 & -0.12 & 0.47 & 0.45 & 0.2 & 0.088 & 0.16 & -0.21 & 1 & 0.48 & 0.94 & -0.0093 & 0.036 & 0.62 \\
\hline $\mathrm{NO2}$ & -0.17 & 0.05 & 0.4 & 0.43 & 0.18 & 0.12 & 0.17 & -0.17 & 0.48 & 1 & 0.72 & 0.081 & -0.056 & 0.51 \\
\hline NOx & -0.2 & -0.062 & 0.5 & 0.49 & 0.2 & 0.11 & 0.18 & -0.23 & 0.94 & 0.72 & 1 & 0.009 & 0.013 & 0.68 \\
\hline Ozone - & 0.23 & 0.036 & -0.17 & -0.052 & -0.23 & 0.17 & -0.019 & 0.14 & -0.0093 & 0.081 & 0.009 & 1 & -0.058 & -0.0066 \\
\hline $\mathrm{SO} 2$. & 0.13 & 0.13 & 0.13 & 0.075 & -0.34 & -0.069 & -0.11 & -0.068 & 0.036 & -0.056 & 0.013 & -0.058 & 1 & -0.02 \\
\hline co & -0.086 & -0.085 & 0.52 & 0.5 & 0.2 & 0.094 & 0.087 & -0.14 & 0.62 & 0.51 & 0.68 & -0.0066 & -0.02 & 1 \\
\hline & AT & BP & PM10 & PM2.5 & $\mathrm{RH}$ & $S R$ & WD & ws & NO & NO2 & NOx & Ozone & so2 & co \\
\hline
\end{tabular}

Pearson Correlation Graph for Summer season 2020 (01 March 2020-14 June 2020)

\begin{tabular}{|c|c|c|c|c|c|c|c|c|c|c|c|c|c|c|}
\hline AT - & 1 & -0.27 & -0.46 & -0.5 & -0.59 & 0.26 & -0.11 & 0.25 & -0.42 & -0.34 & -0.44 & 0.48 & 0.095 & -0.089 \\
\hline $\mathrm{BP}$ & -0.27 & 1 & 0.12 & 0.073 & 0.28 & -0.38 & 0.085 & -0.11 & 0.045 & -0.067 & 0.0071 & -0.23 & -0.051 & -0.12 \\
\hline PM10 & -0.46 & 0.12 & 1 & 0.91 & 0.25 & -0.15 & 0.15 & -0.39 & 0.7 & 0.7 & 0.78 & -0.31 & 0.13 & 0.39 \\
\hline PM2.5 & -0.5 & 0.073 & 0.91 & 1 & 0.33 & -0.12 & 0.061 & -0.41 & 0.62 & 0.68 & 0.72 & -0.29 & 0.095 & 0.38 \\
\hline $\mathrm{RH}-$ & -0.59 & 0.28 & 0.25 & 0.33 & 1 & -0.14 & -0.28 & -0.071 & 0.36 & 0.24 & 0.35 & -0.46 & -0.32 & 0.21 \\
\hline SR & 0.26 & -0.38 & -0.15 & -0.12 & -0.14 & 1 & 0.051 & 0.28 & -0.038 & -0.05 & -0.051 & 0.42 & -0.054 & 0.3 \\
\hline WD - & -0.11 & -0.085 & 0.15 & 0.061 & -0.28 & 0.051 & 1 & -0.18 & 0.15 & 0.098 & 0.15 & 0.051 & 0.11 & -0.063 \\
\hline ws - & 0.25 & -0.11 & -0.39 & -0.41 & -0.071 & 0.28 & -0.18 & 1 & -0.28 & -0.38 & -0.36 & 0.18 & -0.14 & -0.12 \\
\hline NO - & -0.42 & 0.045 & 0.7 & 0.62 & 0.36 & -0.038 & 0.15 & -0.28 & 1 & 0.58 & 0.93 & -0.34 & -0.039 & 0.44 \\
\hline $\mathrm{NO2}$ & -0.34 & -0.067 & 0.7 & 0.68 & 0.24 & -0.05 & 0.098 & -0.38 & 0.58 & 1 & 0.81 & -0.36 & 0.14 & 0.38 \\
\hline NOx & -0.44 & 0.0071 & 0.78 & 0.72 & 0.35 & -0.051 & 0.15 & -0.36 & 0.93 & 0.81 & 1 & -0.38 & 0.017 & 0.48 \\
\hline Ozone - & 0.48 & -0.23 & -0.31 & -0.29 & -0.46 & 0.42 & 0.051 & 0.18 & -0.34 & -0.36 & -0.38 & 1 & 0.031 & 0.066 \\
\hline $\mathrm{SO} 2$ & 0.095 & -0.051 & 0.13 & 0.095 & -0.32 & -0.054 & 0.11 & -0.14 & -0.039 & 0.14 & 0.017 & 0.031 & 1 & -0.16 \\
\hline $\mathrm{CO}$ & -0.089 & -0.12 & 0.39 & 0.38 & 0.21 & 0.3 & -0.063 & -0.12 & 0.44 & 0.38 & 0.48 & 0.066 & -0.16 & 1 \\
\hline & AT & BP & PM10 & PM2.5 & RH & SR & WD & ws & NO & NO2 & NOx & Ozone & $\mathrm{SO} 2$ & CO \\
\hline
\end{tabular}


Pearson Correlation Graph for Monsoon season 2020 (15 June 2020-15 September 2020)

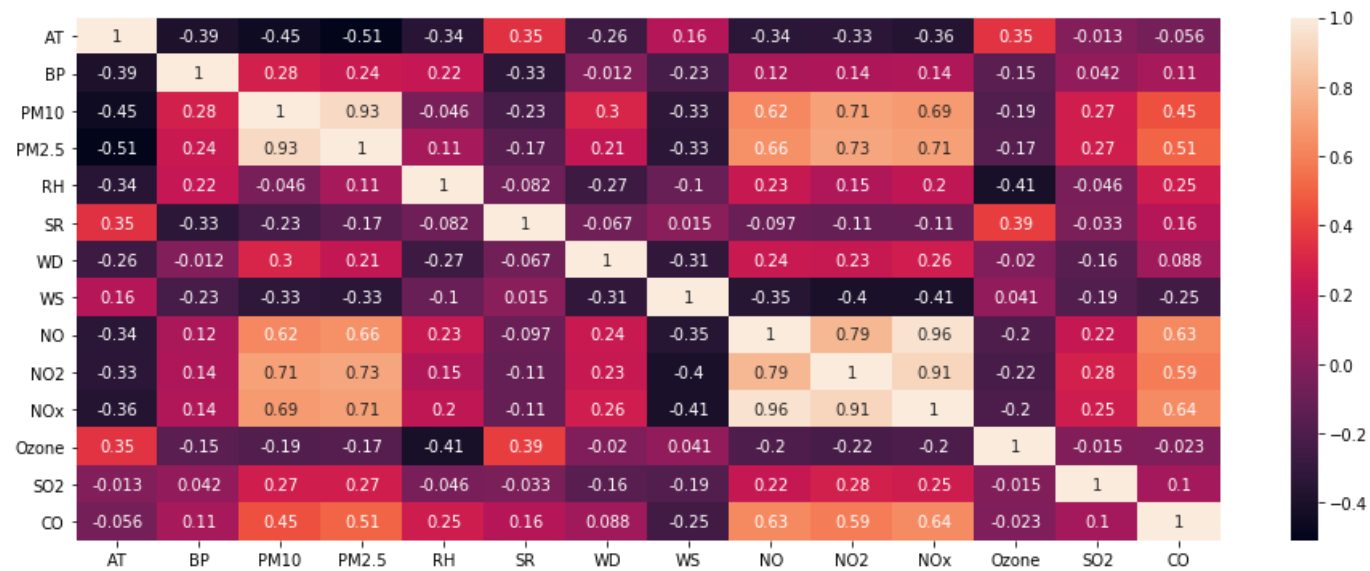

Pearson Correlation Graph for Post Monsoon season 2020 (16 September 2020-14 October 2020)

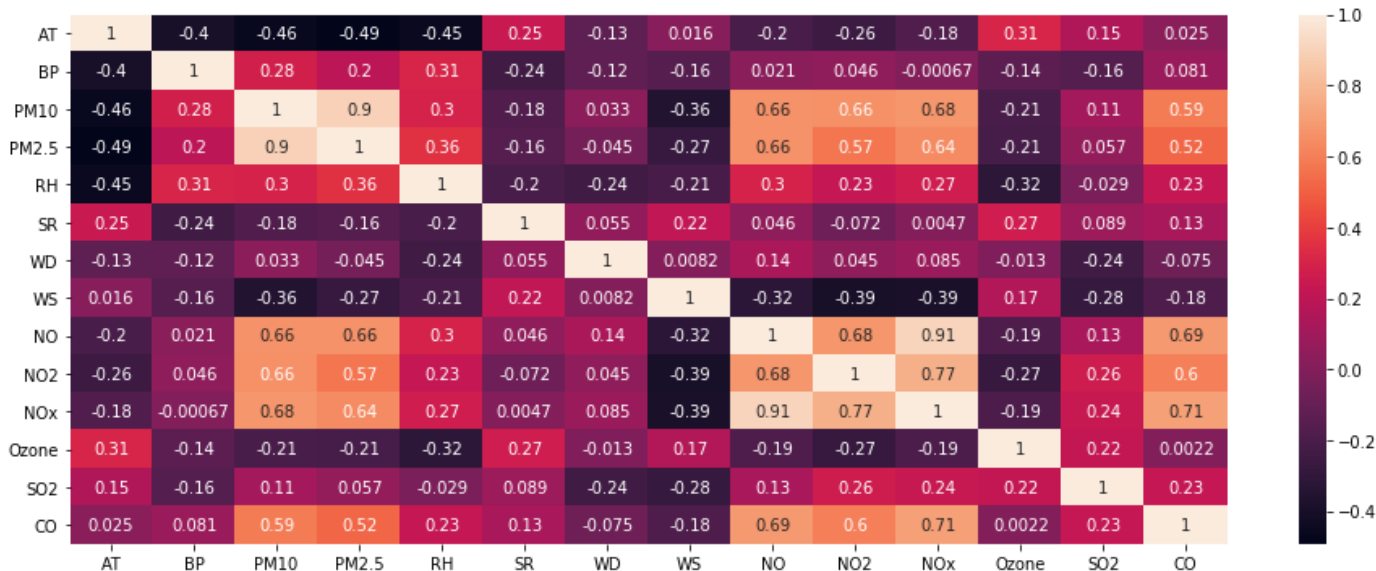

Pearson Correlation Graph during the arrival of winter season 2020 (15 October 2020-08 December 2020)

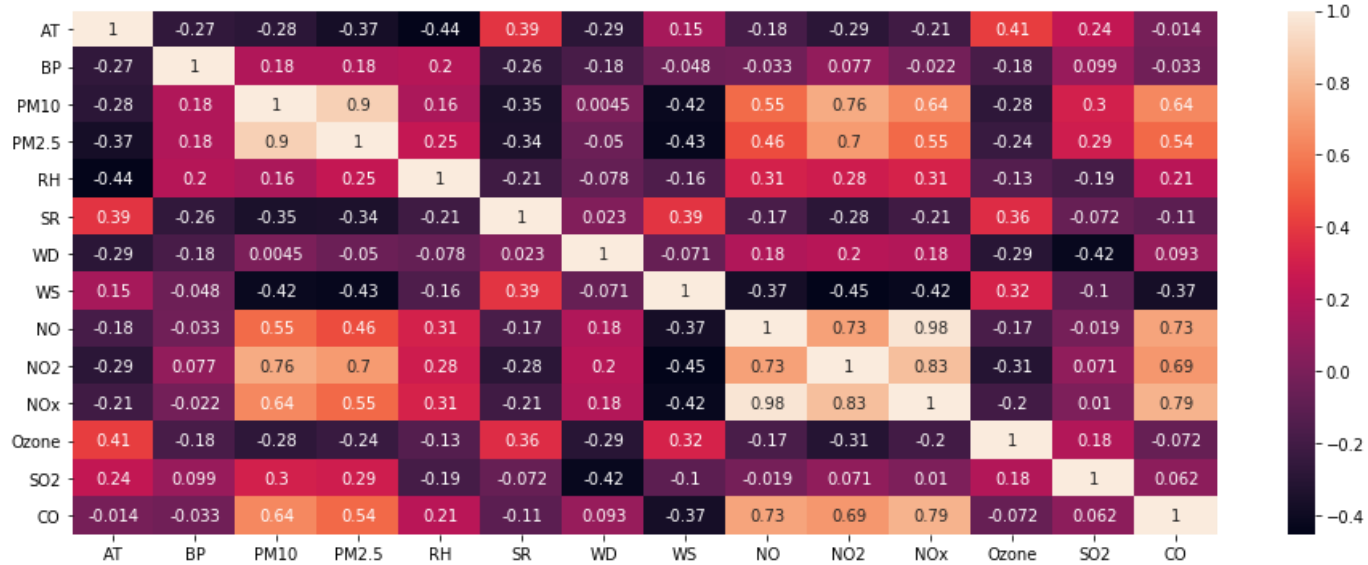

Figure 5 Pearson Correlation between the meteorological parameters and the AQI variables for the year 2019 and 2020 for various spatial variations distinguished as Winter, Summer, Monsoon and Post Monsoon. These graph shows the values between +1 which indicates perfect positive correlation and -1 as perfect negative correlation between two variables; whereas 0 defines there is no relation between the two parameters. 
Table 1

\begin{tabular}{|c|c|c|c|c|c|c|}
\hline Season & & PM10 & & & PM2.5 & \\
\hline & mean & std & median & mean & std & median \\
\hline $\begin{array}{l}\text { Winter Jan - } \\
\text { Feb } 2019\end{array}$ & 243.6452 & 142.6126 & 218.3125 & 138.8241 & 100.7761 & 109.625 \\
\hline $\begin{array}{c}\text { Summer } \\
2019\end{array}$ & 204.7874 & 127.0431 & 189.875 & 92.45261 & 80.28339 & 71.8125 \\
\hline $\begin{array}{c}\text { Monsoon } \\
2019 \\
\end{array}$ & 149.2473 & 117.1216 & 111.6875 & 63.70992 & 59.11406 & 43.3125 \\
\hline $\begin{array}{c}\text { Post } \\
\text { Monsoon } \\
2019 \\
\end{array}$ & 304.792 & 153.0923 & 279.6875 & 155.8028 & 101.3033 & 124.375 \\
\hline $\begin{array}{c}\text { Winter } \\
\text { 2019_2020 }\end{array}$ & 250.724 & 148.6814 & 217.4375 & 140.7799 & 103.6045 & 110.25 \\
\hline $\begin{array}{c}\text { Summer } \\
2020 \\
\end{array}$ & 153.77 & 116.4142 & 117.4375 & 75.10849 & 73.39781 & 50.3125 \\
\hline $\begin{array}{c}\text { Monsoon } \\
2020 \\
\end{array}$ & 121.7836 & 124.9092 & 78.5625 & 57.16338 & 80.58666 & 32.25 \\
\hline $\begin{array}{c}\text { Post } \\
\text { Monsoon2020 } \\
\end{array}$ & 177.3828 & 125.7239 & 144.9375 & 81.09933 & 105.488 & 53.0625 \\
\hline Winter 2020 & 273.4502 & 147.9139 & 272.3125 & 150.7106 & 93.03634 & 148.25 \\
\hline
\end{tabular}

To end the analysis part of this research we have done the PM 2.5 estimation using the ensemble modelling techniques of machine learning algorithms using the Random Forest Technique and Extra tree regressor techniques because these tend to provide better estimated results and works better on the non-linear data (air-pollutants does have non-linear behaviour) than other machine learning techniques like neural networks, linear regression and SVMs (Masih, A, 2019). This ensembled technique is based on supervised machine learning approach which can be used for both classification and regression. 
In these ensembled modelling techniques all the independent variables are directing towards the same problem, further by averaging the results of all the independent variables we are able to get the good estimation of the dependent variable (Bashir, Barjeece, et al, 2019). In this type of techniques one of the advantages is that it combines both the weak and strong predictor variables that helps in reducing the overfitting of the variables on the training data and makes it more generalized for good estimation on the testing data. The $\mathrm{R}^{2}$ value has been observed for both the ensemble modelling techniques to determine how precise estimation of PM2.5 we are able to get using the Random Forest and Extra Trees Regressor algorithm because the $\mathrm{R}^{2}$ value is a statistical measurement which explains the variance of dependent variable based on the independent variables of a regression model; secondly, we look for the root mean square error which is the difference between the predicted values and the observed values. We have also observed the feature importance of the variables using the permutation techniques on both these models to get the features which are impacting the most to the dependent variable PM2.5.

The data has been divided into $80 \%$ training data and $20 \%$ is the testing data and dropping the variable PM10. The n_estimator or the number of trees that has been used in the Random Forest technique is 100 and for the ExtraRegressor forest technique number of decision trees are 200.

The $\mathrm{R}^{2}$ coefficient value for random forest is 0.7562 with root square mean error value is 0.05939 and $R^{2}$ value for extra regressor trees is 0.7841438195727846 with root square mean error value is 0.06 . The fig 6 is the graphical representation of the predicted and observed values of all the four regions of Delhi that has been taken for case study using the random forest ensembled algorithm and fig7 shows the graphical representation of measured and predicted values of PM 2.5 using the extra trees regressor algorithm.

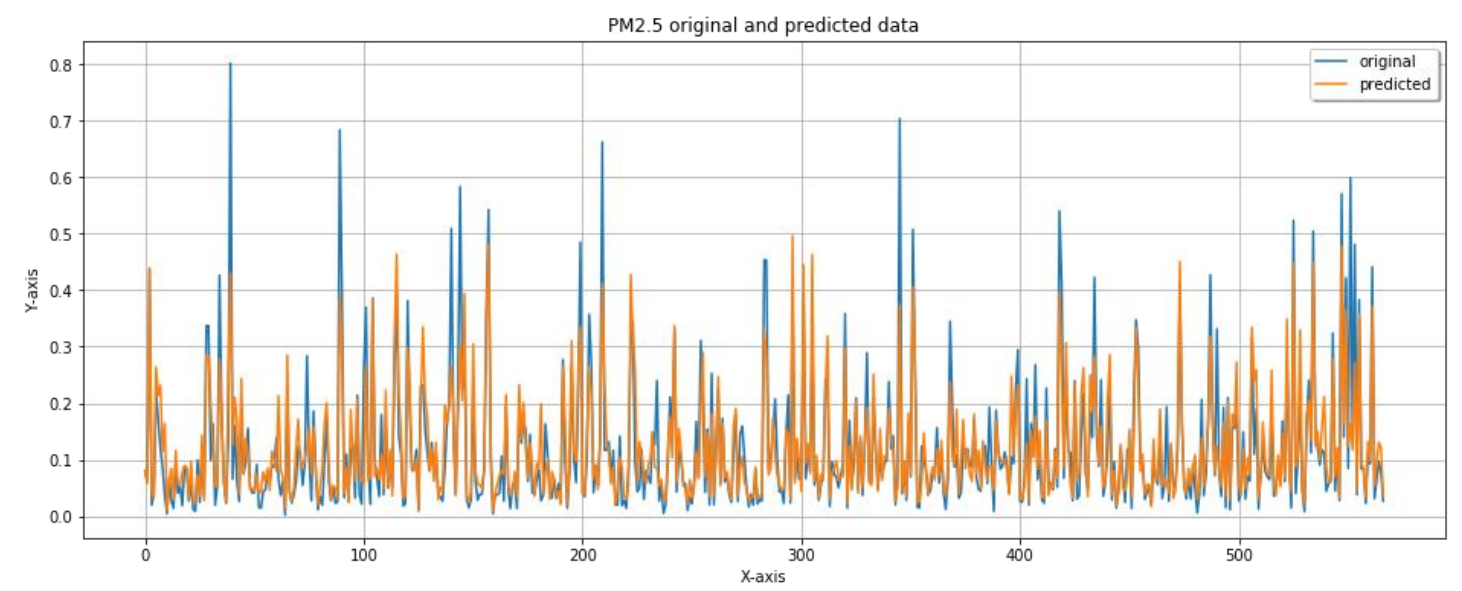

Figure 6 predicted and observed values of PM2.5 using the Random forest algorithm. 


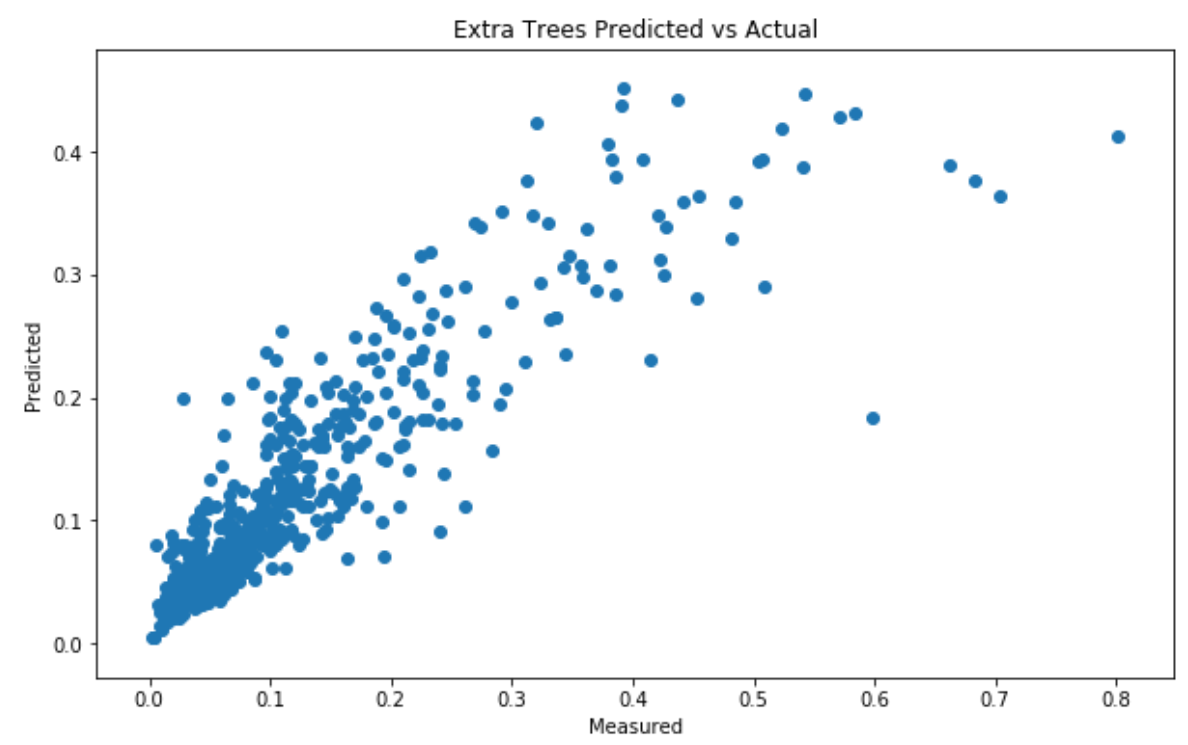

Figure 7 Predicted and measured value of PM 2.5 using the Extra trees regressor algorithm

In figures (fig 8, fig 9) the permutation method has been used on the both the algorithms to extract the features which impact the PM 2.5 level the most and able to observe that the meteorological variables like Ambient Temperature and Solar Radiation and Relative Humidity have quite an impact on the air pollutant PM2.5.

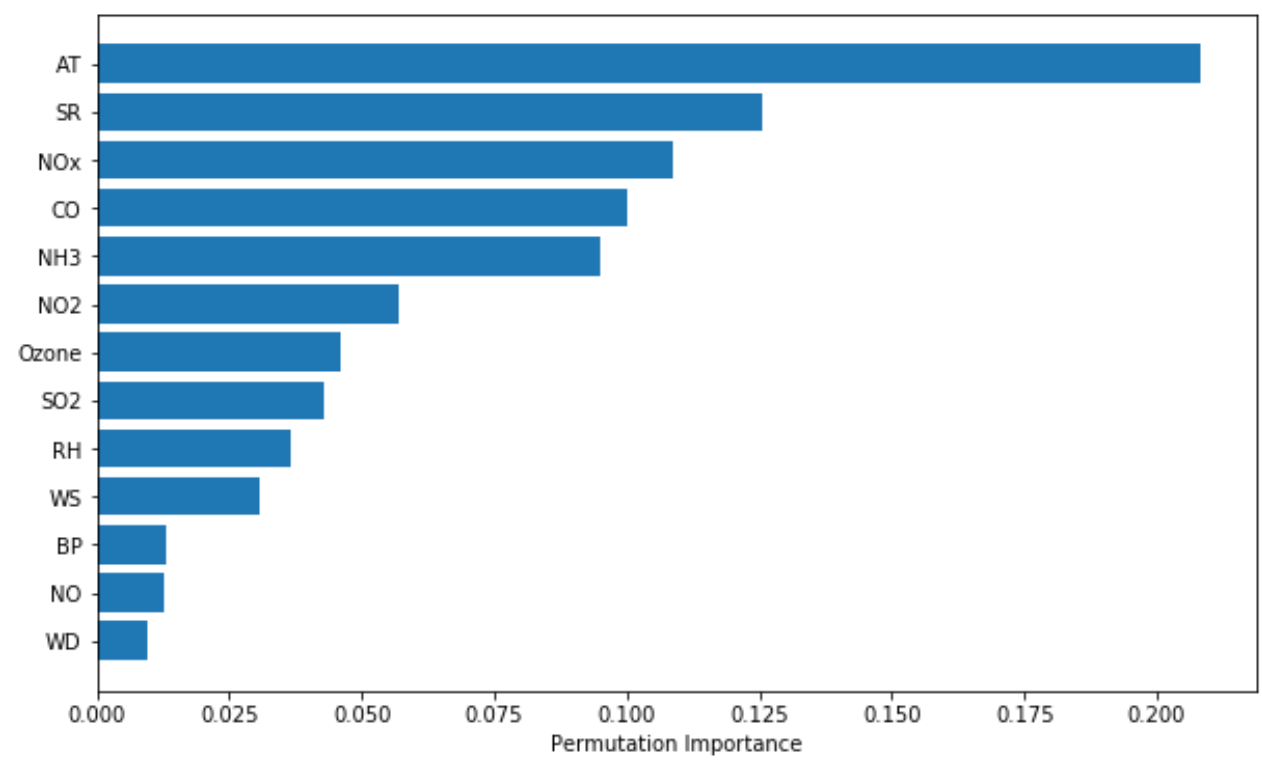

Figure 8 feature importance using the permutation method on the random forest algorithm 


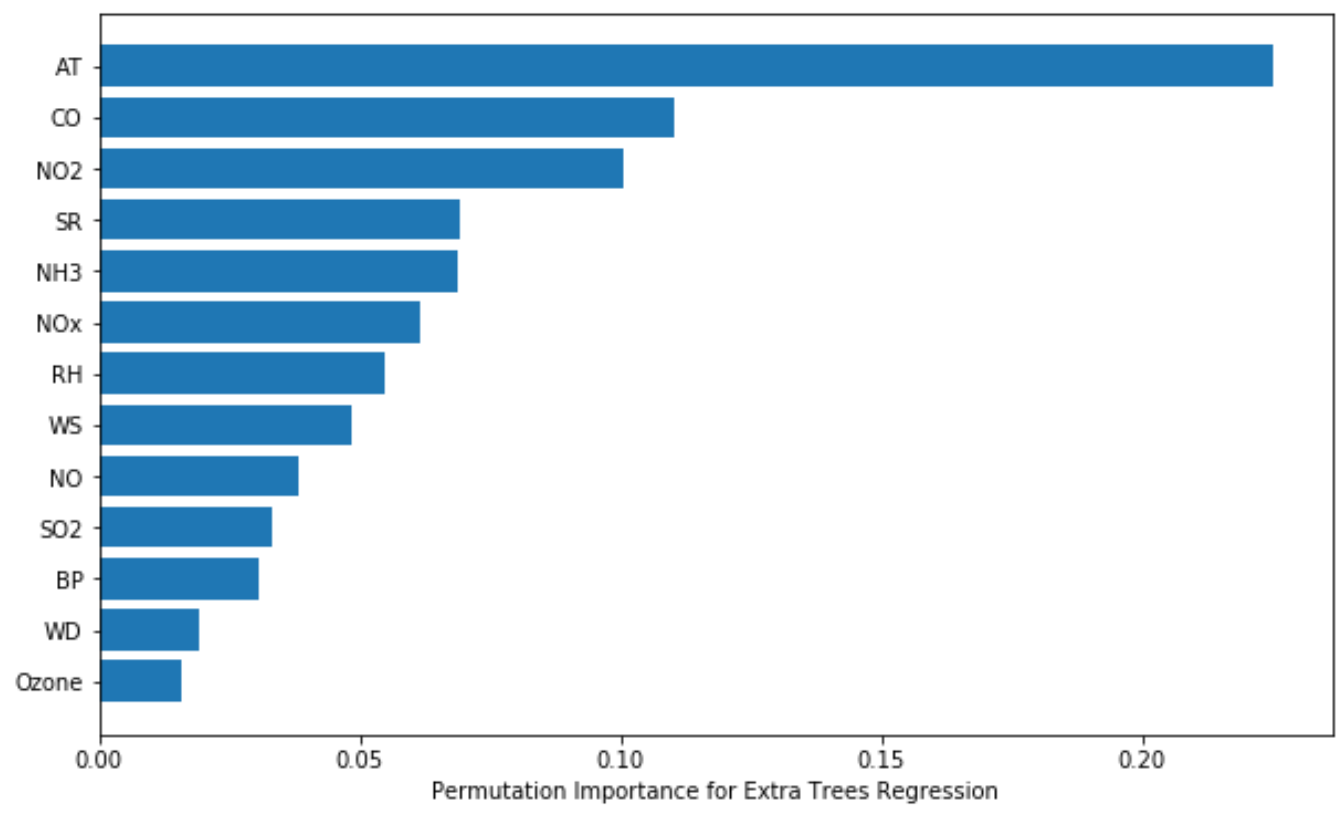

Figure 9 feature importance using permutation technique on extra trees regression model

In the paper we looked for the patterns and trends of air pollutant variables specifically PM10 and PM2.5 during the implementation of odd-even policy in the month of November (04 November 2019 to $15^{\text {th }}$ November 2019) and during the lockdown period $23^{\text {rd }}$ March 2020 to $31^{\text {st }}$ August 2020 for the four regions of Delhi i.e. Ashok Vihar, Anand Vihar, Dwarka and R.K.Puram. Though the reason behind implementation of the policy is great to control the air pollution in city but the results that we are able to observe shows that intervention of the policy is not much successful in curbing the air pollution situation. During the time of Delhi government policy interventions, the meteorological conditions are not favourable (Gandhi, Geetika, et al, 2016) in addition to that, other parameters like micro climatic conditions, anthropogenic activities, stubble burning, domestic fuel burning, burning of Municipal Solid Waste (MSW) and industrial pollution does play a great role in aggravating the air pollution scenario in Delhi. On the other hand, a great deterioration in PM2.5 and PM10 level was seen during the lockdown period where the PM2.5 level had reached below 25 micrograms per metre cube and PM10 level had reached below 50 micrograms per metre cube because the industrial, institutional, regional, commercial activities and many of anthropogenic activities had been restricted which caused a major impact on the pollutant levels in Delhi (Chauhan, Akshansha, et al, 2020). 
Spatial variation does play a major role in determining the pollutant levels. As we able to analyse that meteorological parameters like Ambient temperature, relative humidity, wind speed, wind direction and solar radiation have a different impact on different time of seasons (summer, monsoon, post-monsoon and winters). Thus, maximum level or the outliers of PM10 and PM2.5 above the threshold level i.e., greater than 0.95 are observed during the winter season and most of the minimum values less than the threshold level of 0.05 was observed during the monsoon period (Hama, Sarkawt M.L., et al 2020).

Lastly, to have good prediction of PM2.5 level, Random Forest and Extra Trees Regressor algorithm is used; which provides accurate estimation with $\mathrm{R}^{2}$ value of 0.75 and 0.78 respectively of PM2.5 for all the four regions of Delhi. This provides us a good idea that ensemble techniques specifically by using the Random Forest techniques could give us good estimation of the pollutant levels than other machine learning algorithms (Bashir, Barjeece, et al, 2019) (Masih, A, 2019). This study further will be expanded by inclusion of other parameters like micro-climatic conditions for each region, anthropogenic activities during the weekends and weekdays and all this will be based on important features \& findings that is introduced in this paper.

\section{Acknowledgement}

I would like to express my gratitude towards my organization and colleagues for giving me an opportunity to complete this research paper. A sincere thanks to them.

\section{References}

Masih, A. Machine learning algorithms in air quality modelling 2019. Global Journal of Environmental Science and Management.

Bloss.J.William, Goodman. Paul, Hama.M.L.Sarkawt, Harrison.M.Roy, Khare.Mukesh, Kumar Prashant, Namdeo Anil, Sharma Chhemendra, Sokhi Ranjeet. Four-year assessment of ambient particulate matter and trace gases in the Delhi-NCR region of India, Sustainable Cities and Society, Volume 54, 2020.

Abdurrahman Isa Muhammad, Chaki Sukalpaa, Gaurav Saini. Stubble burning: Effects on health \& environment, regulations and management practices, Environmental Advances, Volume 2, 2020. 
Cao Chunxiang, Bashir Barjeece, Joharestani Zamani Mehdi, Ni Xiliang, Talebiesfandarani Somayeh. $\mathrm{PM}_{2.5}$ Prediction Based on Random Forest, XGBoost, and Deep Learning Using Multisource Remote Sensing Data. Atmosphere. 2019

WHO Air_Pollution https://www.who.int/health-topics/air-pollution\#tab=tab_1

IQAir World Air Quality Report 2019 https://www.iqair.com/world-most-polluted-cities

Chauhan Akshansha, Singh P. Ramesh. Impact of Lockdown on air quality in India during Covid-19 pandemic. Nature Public Health Emergency Collection 2020.

Gandhi Geetika, Goyal P. Assessment of Air Quality during the odd-even scheme of vehicles in Delhi. 2016. Indian Journal of Science and Technology.

Arif Mohammad, Eric Zusman, Gourav Piyush, Kumar Ramesh, Kumar Rajesh. Ambien Black Carbon, PM2.5 and PM10 at Patna: Influence of anthropogenic emissions and brick kilns Science of The Total Environment, Volume 624, 2018, Pages 1387-1400.

Gulia Sunil, Harrison M Roy, Khare Mukesh, Kumar Prashant. The influence of odd-even car trial on fine and coarse particles in Delhi, Environmental Pollution, Volume 225, 2017, Pages 20-30.

Ghosh Gopal Krishna, Mahato Susanta, Pal Swades. Effect of lockdown amid COVID-19 pandemic on air quality of the megacity Delhi, India, Science of The Total Environment, Volume 730, 2020.

De Vito, Laura \& Chatterton, Tim \& Namdeo, Anil \& SM, Shiva Nagendra \& Gulia, Sunil \& GOYAL, SANJIV \& Bell, Margaret \& Goodman, Paul \& Longhurst, J. \& Hayes, Enda \& Kumar, Rakesh \& Sethi, Virendra \& Ramadurai, Sengupta \& Majumdar, Shoban \& Menon, Jyothi \& Turamari, Mallikarjun \& Barnes, Jo. (2018). Air pollution in Delhi: A review of past and current policy approaches. WIT Transactions on Ecology and the Environment. 230. 441451. 10.2495/AIR180411.

Gharad Prathamesh, Nanivadekar Rurika, Paradkar Aishwarya. Research report Delhi air pollution 2016. International Journal of Science Technology and Management. Vol.No.5, Issue No.03, March 2016.

Chate M.D., Barth C.M., Beig.G, Fadnavis S., Ghude D.Sachin, Jena C., Kumar R., Pfister G.G., Pithani Prakash. Premature Mortality in India due to PM2.5 and Ozone exposure. 27 April 2016. 
Gupta Kumar Sanjiv, Nongkynrih Baridalyne, Rizwan SA. Air pollution in Delhi: Its magnitude and effect on health 2013. Indian Journal of Community Medicine. 